\title{
METALLIZED SOLID ROCKET PROPELLANTS BASED ON AN/AP AND PSAN/AP FOR ACCESS TO SPACE
}

\author{
S. Levi, D. Signoriello, A. Gabardi, M. Molinari, \\ L. Galfetti, L. T. DeLuca, S. Cianfanelli, and G. F. Klyakin
}

Solid rocket propellants based on dual mixes of inorganic crystalline oxidizers (ammonium nitrate (AN) and ammonium perchlorate (AP)) with binder and a mixture of micrometric-nanometric aluminum were investigated. Ammonium nitrate is a low-cost oxidizer, producing environment friendly combustion products but with lower specific impulse compared to AP. The better performance obtained with AP and the low quantity of toxic emissions obtained by using AN have suggested an interesting compromise based on a dual mixture of the two oxidizers. To improve the thermal response of raw AN, different types of phase stabilized AN (PSAN) and AN/AP co-crystals were investigated.

\section{NOMENCLATURE}

$\begin{array}{ll}\text { Al_06_M } & \text { micrometric aluminum with flakes size of } 50 \mu \mathrm{m} \\ \text { Al_06_F } & \text { micrometric aluminum with spherical flakes } \\ \text { AN } & \text { ammonium nitrate } \\ \text { AP } & \text { ammonium perchlorate } \\ \text { M-nano } & \text { nanometric aluminum } \\ \text { PSAN } & \text { phase stabilized AN } \\ \text { PSANco-cry } & \text { PSAN co-crystallized with AP } \\ n & \text { pressure exponent } \\ p & \text { pressure, bar } \\ r_{b} & \text { burning rate } \mathrm{mm} / \mathrm{s} \\ \rho & \text { density, } \mathrm{g} / \mathrm{cm}^{3}\end{array}$

\section{BACKGROUND}

Ammonium nitrate, an inorganic solid oxidizer already used in rocket propulsion years ago, is still a widely employed oxidizer yielding, with common organic 
fuels and under thermochemical equilibrium, combustion products with no environmentally harmful constituents. Its relatively low enthalpy of formation is balanced by the low cost of the commercial grade product. Another advantage of AN-based compositions consists in comparatively low sensitivity to mechanical stimuli. Nevertheless, at this stage of development of reduced-cost space launchers, all available information concerning the fundamental performance of AN-based energetic materials should be reviewed, with particular attention to their ballistic properties and the actually delivered performance.

Solid rocket propellants currently used in space launchers release, after combustion, a large amount of substances toxic for people and polluting for the environment ( $\mathrm{HCl}$, notably). Indeed, current compositions use AP as oxidizer, an inorganic ammonium salt capable of an elevated oxidizing power and therefore satisfactory specific impulse. However, in its reverse of the formal formation reaction, every mole of AP produces two moles of oxygen and also half-a-mole of chlorine [1]:

$$
\mathrm{NH}_{4} \mathrm{ClO}_{4} \rightarrow \frac{1}{2} \mathrm{~N}_{2}+\frac{1}{2} \mathrm{Cl}_{2}+2 \mathrm{O}_{2}+2 \mathrm{H}_{2} .
$$

Successively, chlorine reacts with other elements released during combustion and generates several polluting substances.

In this work, new propellants aiming at space access and environmental protection are studied. Use of AP was minimized and its presence replaced, partially or totally, by AN. The AN molecule generates nonpolluting combustion products and thus can virtually be considered a green oxidizer; besides, raw AN costs about one tenth of AP. Both reasons make AN an attractive option for solid rocket propellant formulation. Nevertheless, employment of AN in space propulsion is not recommended due to a series of negative facts with respect to AP:

- high hygroscopicity: AN crystals easily absorb humidity and expand thus suffering a decrease in density, volumetric specific impulse, and mechanical properties;

- low density: $1.73 \mathrm{~g} / \mathrm{cm}^{3}$ for AN against $1.95 \mathrm{~g} / \mathrm{cm}^{3}$ for AP;

- limited oxidation capacity: lower oxygen percentage and decomposition are characterized by a lower monopropellant flame temperature (at 70 bar, $1247 \mathrm{~K}$ for AN against $1405 \mathrm{~K}$ for AP);

- several polymorphic phase transitions occurring at $-16.9,+32.3,+84.2$, and $+125^{\circ} \mathrm{C}$. The subsequent volumetric changes create mechanical strains that may damage the propellant grain under cyclic variations of temperature. The most disturbing transition is at $+32.3{ }^{\circ} \mathrm{C}$, involving a volumetric variation of about $6 \%$ at a temperature level easily reached during storage; 
- a liquid melting layer accompanies AN combustion; and

- difficult burning in the absence of catalysts.

All of these facts lead in general to the inferior ballistic performance of ANbased propellants with respect to AP-based propellants, and underline:

- relatively low volumetric and weight specific impulses;

- low burning rate, little affected by particle size but strongly sensitive to pressure and initial temperature; and

- low quality of combustion, with high values of pressure deflagration limit (PDL) and low reactivity at low pressures.

To be technically competitive, AN-based propellants should match the following requirements:

- energy characteristics close to those of the current AP-based propellants;

- absence of AN polymorphic transformations at the expected operating temperatures;

- a satisfactory steady burning rate law (level and sensitivity);

- modest level of specific impulse losses.

For the above reasons, AN applications in space propulsion require additives able to improve the ballistic performance. They should be, at the same time, low-cost and environmentally compatible. Considering the good propulsive performance of the relatively expensive AP and the low environmental impact of the low-cost AN, use of dual-oxidizer AN + AP compositions, with the prevalence of $\mathrm{AN}$, seems a good compromise between the two options.

To improve the ballistic performance, metallic additives were investigated. In particular, bimodal micrometric-nanometric aluminum mixtures were tested. On the one hand, the introduction of nanometric $\mathrm{Al}(\mathrm{nAl})$ powders is known [2-4] to increase steady burning rates and reduce the size of condensed combustion products. On the other hand, $\mathrm{nAl}$ suffers production costs larger than micrometric $\mathrm{Al}(\mu \mathrm{Al})$ and may cause deterioration of mechanical properties. Moreover, using $\mathrm{nAl}$ may involve less effective damping of pressure fluctuations in a combustion chamber.

The presence of polymorphic transformations in the AN crystal is another important problem to be solved, if AP compositions have to be replaced by AN compositions. In this respect, PSAN or AN/AP co-crystals offer a possible solution. Phase stabilization of $\mathrm{AN}$ is carried out by resorting to various additives. The presence of these additives should not affect the energy characteristics of $\mathrm{AN}$, while intensifying its thermal decomposition and promoting combustion. 
The reduced specific impulse and density, with respect to the widely used AP, make AN an oxidizer less than ideal for space propulsion. However, the suggested dual oxidizer system allows one to reach a convenient trade-off between the two ingredients. Thus, the long-range objectives of this research program is to identify the (PSAN + AP)-based formulations suitable for space exploration. The specific objective of this work is a trade-off analysis to identify the combination of $\mu \mathrm{Al}$ and $\mathrm{nAl}$ and the PSAN-AP mixtures optimizing ballistic performance, cost, and environmental impact.

\section{PHASE STABILIZED AMMONIUM NITRATE}

As a modifier of the crystalline lattice low-cost potassium nitrate was mainly used [5], while magnesium nitrate was investigated as inhibitor of kinetic processes at transitions. In the first stage of this research program, these ingredients were introduced into AN by co-crystallization from melts. The transition energy IV-III $(1,7 \mathrm{~kJ} / \mathrm{mol})$ of AN, containing $4 \%$ of the binary potassium nitratemagnesium nitrate additive, reveals a minimum if plotted vs. the magnesium nitrate mass fraction. Thus, AN with the addition of the investigated ingredients is stable within the limits from -50 up to $+90{ }^{\circ} \mathrm{C}$. A similar picture of phase stability is obtained by introducing into AN a binary additive, one of the ingredients in which can virtually be any inorganic salt of potassium [6].

In a second phase of this research program, an increase of AN thermal decomposition was aimed at while preserving its phase stability. Salts of chromium are the best among the known catalysts of AN thermal decomposition and combustion. Therefore, potassium nitrate in the binary addition was partially or completely replaced by potassium dichromate. Phase-stabilized AN containing $5 \%-6 \%$ of combined additive, with different structure, was used in all model solid propellants tested in this work.

The substitution of raw AN by PSAN allows one to solve the problems with phase transitions.

\section{METALLIZED DUAL-OXIDIZER FORMULATIONS}

Table 1 lists ten metallized AN + AP dual-oxidizer formulations investigated at Politecnico di Milano - SPLab. All of them contain $68 \%$ raw AN $+\mathrm{AP}$ (in the ratio 0.6 raw $\mathrm{AN}+0.4 \mathrm{AP}$ ), $18 \%$ aluminum (in bimodal mixture), and $14 \%$ inert binder composed by hydroxyl-terminated polybutadiene (HTPB) R45 , dioctyladipate (DOA), and isophorone diisocyanate (IPDI). The ten tested formulations differ only by the kind (two) of $\mu \mathrm{Al}$ and the ratio (five) of $\mathrm{nAl} / \mu \mathrm{Al}$ in the metal powder mixture. 
Table 1 Metallized raw AN + AP dual-oxidizer propellants investigated at SPLab (composition in mass percentage)

\begin{tabular}{|c|c|c|c|c|}
\hline Name & Oxidizer $(68 \%)$ & \multicolumn{2}{|c|}{ Aluminum (18\%) } & Binder (14\%) \\
\hline & & \multicolumn{2}{|c|}{ Micro Al_06M Nano Al_01/a } & \\
\hline M-Nano_0\% & $60 \% \mathrm{AN}$ & $100 \%$ & $0 \%$ & $79,21 \%$ НTPB \\
\hline M-Nano_10\% & $\left(d_{p}<200 \mu \mathrm{m}\right)$ & $90 \%$ & $10 \%$ & + \\
\hline M-Nano_20\% & + & $80 \%$ & $20 \%$ & $13,11 \%$ DOA \\
\hline M-Nano_30\% & $40 \% \mathrm{AP}$ & $70 \%$ & $30 \%$ & + \\
\hline \multirow{2}{*}{ M-Nano_40\% } & $\left(80<d_{p}<140 \mu \mathrm{m}\right)$ & $60 \%$ & $40 \%$ & $7,68 \%$ IPDI \\
\hline & & Micro Al_05F & Nano Al_01/a & \\
\hline F-Nano_0\% & $60 \% \mathrm{AN}$ & $100 \%$ & $0 \%$ & $79,21 \%$ НТРВ \\
\hline F-Nano_10\% & $\left(d_{p}<200 \mu \mathrm{m}\right)$ & $90 \%$ & $10 \%$ & + \\
\hline F-Nano_20\% & + & $80 \%$ & $20 \%$ & $13,11 \%$ DOA \\
\hline F-Nano_30\% & $40 \% \mathrm{AP}$ & $70 \%$ & $30 \%$ & + \\
\hline F-Nano_40\% & $\left(80<d_{p}<140 \mu \mathrm{m}\right)$ & $60 \%$ & $40 \%$ & $7,68 \%$ IPDI \\
\hline
\end{tabular}

Two types of $\mu \mathrm{Al}$ were used: the first, called Al_06M, is a commercial aluminum powder made by flakes with a characteristic size of $50 \mu \mathrm{m}$ and BrunauerEmmett-Teller (BET) specific surface area $<0.1 \mathrm{~m}^{2} / \mathrm{g}$; the second type, called Al_05F, is a propulsive grade aluminum made by spherical particles with a characteristic size of $30 \mu \mathrm{m}$ and specific surface area of $0.1 \mathrm{~m}^{2} / \mathrm{g}$. The $\mathrm{nAl}$,

Table 2 Density of metallized raw AN + AP dual-oxidizer propellants investigated at SPLab

\begin{tabular}{lcc}
\hline \multicolumn{1}{c}{ Name } & $\begin{array}{c}\text { Density, } \\
\mathrm{g} / \mathrm{cm}^{3} \\
\text { (measured) }\end{array}$ & $\begin{array}{c}\text { Density, } \\
\mathrm{g} / \mathrm{cm}^{3} \\
\text { (theoretical) }\end{array}$ \\
\hline M-Nano_0\% & 1.566 & \\
M-Nano_10\% & 1.587 & \\
M-Nano_20\% & 1.652 & 1.680 \\
M-Nano_30\% & 1.640 & \\
M-Nano_40\% & 1.603 & \\
\hline F-Nano_0\% & 1.586 & \\
F-Nano_10\% & 1.550 & 1.680 \\
F-Nano_20\% & 1.622 & \\
F-Nano_30\% & 1.655 & \\
F-Nano_40\% & 1.676 & \\
\hline
\end{tabular}
called Al_01/a, was produced uncoated in Russia by the electrical explosion of wires (EEW) technique similarly to Alex; the characteristic size of the spherical particles is about $117 \mathrm{~nm}$ and its specific surface area is $15.3 \mathrm{~m}^{2} / \mathrm{g}$, while the total $\mathrm{Al}$ content is $96.5 \%$. Nanometric $\mathrm{Al}$ additive ranged from $0 \%$ up to $40 \%$ of the total metal fraction present in the propellant.

Table 2 reports the measured and calculated density values of all manufactured propellants, assuming for metallic $\mathrm{Al}$ its bulk density. The MNano_20\% and the F-Nano_40\% formulations show the closest density to the calculated value. 
Table 3 Details of metallized PSANco-cry dual-oxidizer propellants (composition in mass percentage)

\begin{tabular}{|c|c|c|c|c|c|c|}
\hline Propellant & $\begin{array}{l}\mathrm{AN} / \mathrm{AP} \\
\text { in mass }\end{array}$ & Aluminum & Binder & Oxidizer & $\begin{array}{c}\text { Grain size, } \\
\mu \mathrm{m}\end{array}$ & $\begin{array}{l}\rho_{\text {theor }}, \rho_{\text {meas }}, \\
\mathrm{g} / \mathrm{cm}^{3} \mathrm{~g} / \mathrm{cm}^{3}\end{array}$ \\
\hline Co-cry_(200-400) & 1.502 & Al_06 18\% & $14 \%$ & $68 \%$ Co-cry & $200-400$ & $1.693 \quad 1.600$ \\
\hline Co-cry_(200) & 1.502 & Al_06 18\% & $14 \%$ & $68 \%$ Co-cry & $<200$ & $\begin{array}{ll}1.693 & 1.621\end{array}$ \\
\hline$\overline{\text { Co-cry_(70) }}$ & 1.502 & Al_06 18\% & $14 \%$ & $68 \%$ Co-cry & $<70$ & $\begin{array}{ll}1.693 & 1.678\end{array}$ \\
\hline Co-cry_bimodal & 1.502 & Al_06 18\% & $14 \%$ & $68 \%$ Co-cry & $\begin{array}{c}40 \% \quad 200-400 \\
28 \% \quad 80-140\end{array}$ & $1.693 \quad 1.680$ \\
\hline Co-cry-AP & 0.525 & Al_06 18\% & $14 \%$ & $\begin{array}{l}40 \% \text { Co-cry, } \\
28 \% \text { AP }\end{array}$ & $\begin{array}{c}\text { Co-cry }<70 \\
\text { AP } 80-140\end{array}$ & 1.7201 .709 \\
\hline Co-cry SPLab & 1 & Al_06 18\% & $14 \%$ & $68 \%$ Co-cry & $\begin{array}{l}40 \% 200-400 \\
28 \% \quad 80-140\end{array}$ & $1.696 \quad 1.660$ \\
\hline
\end{tabular}

For the test conditions explored, this suggests a better propellant matrix with respect to the remaining formulations.

Table 3 lists and provides details about the metallized PSAN-AP cocrystallized dual-oxidizer propellants investigated at SPLab.

Co-cry is an oxidizer produced in the South Russia Technical University through co-crystallization in a watery solution of $\mathrm{AN}, \mathrm{AP}, \mathrm{K}_{2} \mathrm{Cr}_{2} \mathrm{O}_{7}$, and $\mathrm{Mg}\left(\mathrm{NO}_{3}\right)_{2}$. Its mass percentage composition is $56.5 \% \mathrm{AN}, 37.6 \% \mathrm{AP}$, $5 \% \mathrm{~K}_{2} \mathrm{Cr}_{2} \mathrm{O}_{7}$, and $0.9 \% \mathrm{Mg}\left(\mathrm{NO}_{3}\right)_{2}$.

Co-cry SPLab is an oxidizer produced in SPLab through co-crystallization of $\mathrm{AN}, \mathrm{K}_{2} \mathrm{Cr}_{2} \mathrm{O}_{7}, \mathrm{KCl}, \mathrm{Mg}\left(\mathrm{NO}_{3}\right)_{2}$, and $\mathrm{AP}$. It is prepared through the cocrystallization method, from a watery solution, where all salts are in the form of eutectic mixture.

Also, PSAN-AP based propellants (not co-crystallized) were investigated using PSAN4 and PSAN5 oxidizers. Oxidizer composition in PSAN4-AP propellant is $40 \%$ of PSAN4 (95\% AN, $3 \% \mathrm{~K}_{2} \mathrm{Cr}_{2} \mathrm{O}_{7}, 1 \% \mathrm{Mg}\left(\mathrm{NO}_{3}\right)_{2}$, and $1 \% \mathrm{KClO}_{4}$ ) and $28 \%$ of AP. Oxidizer composition of PSAN5-AP propellant is characterized by the same composition with the substitution of PSAN4 by PSAN5 (95\% AN, $3 \% \mathrm{~K}_{2} \mathrm{Cr}_{2} \mathrm{O}_{7}, 1 \% \mathrm{Mg}\left(\mathrm{NO}_{3}\right)_{2}$, and $\left.1 \% \mathrm{KCl}\right)$.

\section{EXPERIMENTAL RESULTS}

The experimental ballistic testing systematically carried out at SPLab includes, in particular, the measurement of steady burning rate and ignition delay. Propellants containing AN as oxidizer are characterized by high PDL values. Note that below some critical pressure, only the oxidizer takes part in the combustion 
process and the sample leaves a carbon skeleton with a size comparable to that of the burning sample. For the investigated propellants, this critical pressure was about 10 bar and therefore, the burning rates were measured at pressures of 20,30 , and 50 bar.

The Nano_0\% propellant (i.e., the formulation containing only $\mu \mathrm{Al}$ ) is characterized by steady burning rates sensibly depending on pressure and lower as compared to those relevant to current space launchers. With increasing the amount of nano-Al, pressure sensitivity decreases whereas steady burning rates increase due to larger specific surfaces. However, for $\mathrm{nAl}$ above $20 \%$, these positive effects tend to vanish, probably due to an increasing influence of chemical kinetics with respect to diffusive mechanism. Thus, the optimum formulation seems to be the one denoted as Nano_20\%, combining suitable burning rates and low pressure sensitivity.

The measured ballistic laws of the tested SPLab propellants are shown in Figs. 1 and 2 and summarized in Table 4. The F-propellants containing spherical $\mu \mathrm{Al}$ exhibit a similar ballistic law as the flaked $\mu \mathrm{Al}$ propellants.

The above experimental results point out that the metallized dual-oxidizer raw $\mathrm{AN}+\mathrm{AP}$ propellants, with bimodal $\mu \mathrm{Al}+\mathrm{nAl}$ in the ratio 0.80 microflakes : 0.20 nano, takes on the ballistic properties approaching those of the current monooxidizer propellants. When using spherical $\mu \mathrm{Al}$, the situation is about the

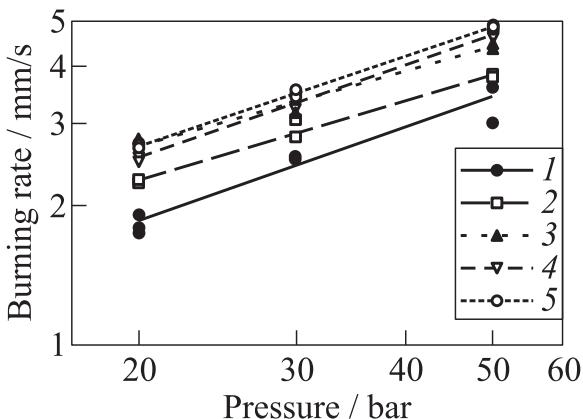

Figure 1 Burning rate vs. pressure for SPLab propellants with flaked $\mu \mathrm{Al}$ (series $\mathrm{M}), r_{b}=a p^{n}: 1-$ Nano_0\%, $a=0.243 \pm 0.050, n=0.678 \pm 0.060$; $2-$ Nano_10\%, $a=0.407 \pm 0.036, n$ $=0.573 \pm 0.026 ; 3-$ Nano_20\%, $a$ $=0.537 \pm 0.051, n=0.538 \pm 0.028 ; 4$ Nano_30\%, $a=0.342 \pm 0.026, n=0.668$ $\pm 0.022 ;$ and $5-$ Nano_40\%, $a=0.389$ $\pm 0.016, n=0.644 \pm 0.012$

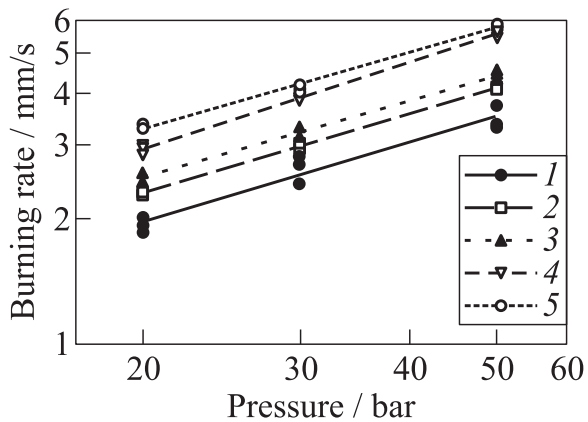

Figure 2 Burning rate vs. pressure for SPLab propellants with spherical $\mu \mathrm{Al}$ (series F), $r_{b}=a p^{n}: 1-$ F-Nano_0\%, $a=0.290 \pm 0.058, n=0.638 \pm 0.058$; $2-$ F-Nano_10\%, $a=0.342 \pm 0.012$, $n=0.636 \pm 0.010 ; 3-$ F-Nano_20\%, $a=0.394 \pm 0.030, n=0.616 \pm 0.022$; 4 - F-Nano_30\%, $a=0.369 \pm 0.019$, $n=0.691 \pm 0.015 ;$ and $5-$ F-Nano_40\%, $a=0.516 \pm 0.034, n=0.616 \pm 0.019$ 
Table 4 Vieille law and granular diffusion flame (GDF) model [7] for SPLab propellants

\begin{tabular}{|c|c|c|c|c|c|c|}
\hline \multirow[b]{2}{*}{ Propellant } & \multirow[b]{2}{*}{ Vieille's law $r_{b}=a p^{n}$} & \multirow[b]{2}{*}{$R^{2}$} & \multicolumn{3}{|c|}{ GDF model $p / r_{b}=a+b p^{2 / 3}$} & \multirow[b]{2}{*}{$R^{2}$} \\
\hline & & & $\begin{array}{c}a, \\
\operatorname{bar} \cdot \mathrm{s} / \mathrm{m}\end{array}$ & $\begin{array}{c}b, \\
\operatorname{ar}^{1 / 3} \mathrm{~s} / \mathrm{m}\end{array}$ & $\begin{array}{c}a / b \\
\mathrm{bar}^{2 / 3}\end{array}$ & \\
\hline$-\mathrm{N}$ & $(0.2$ & 0.931 & 6.219 & 0.625 & 9.950 & 0.791 \\
\hline$[-\mathrm{N}$ & $p^{0}$ & 0.987 & 3.812 & 0.686 & 5.557 & 0.980 \\
\hline [-Nano_20\% & $(0.537 \pm 0.051) p^{0 .}$ & 0.984 & 2.842 & 0.629 & 4.518 & 0.977 \\
\hline $0 \%$ & 26) $p^{0.668 \pm 0.022}$ & 0.993 & 4.639 & 0.450 & 10.309 & .968 \\
\hline $\mathrm{I}-\mathrm{Na}$ & $p^{0.644 \pm 0.012}$ & 0.998 & 4.117 & 0.458 & 8.989 & $0.98-r-r-x$ \\
\hline -Nar & $8) p^{0.638 \pm 0.010}$ & 0.937 & 5.294 & 0.668 & 7.925 & 0.86 \\
\hline$-\mathrm{Na}$ & 12) $p^{0.636 \pm 0.010}$ & 0.998 & 4.645 & 0.554 & 8.384 & 0.995 \\
\hline$-\mathrm{Na}$ & 30) $p^{0.616 \pm 0.022}$ & 0.992 & 4.094 & 0.537 & 7.624 & 0.974 \\
\hline & $p^{0.691 \pm 0.015}$ & 0.997 & 4.234 & 0.357 & 11.860 & 0.983 \\
\hline -Nano_40\% & $(0.516 \pm 0.034) p^{0.616 \pm 0.019}$ & 0.994 & 3.179 & 0.406 & 7.830 & 0.976 \\
\hline
\end{tabular}

same: F-Nano_20\% has a lower multiplicative factor than M-Nano_20\%, a larger pressure sensitivity, and also a bigger $a / b$ ratio in the GDF model. The pressure sensitivity of steady burning rate maintains high for the whole $\mathrm{F}$ series of tested propellants.

\subsection{Burning Rate of PSAN-AP Propellants}

Knowledge of the steady burning rate of the propellants based on PSAN is important to understand the role of additives and to search for ecologically clean compositions featuring ballistic performance comparable to those of AP-based propellants. Previous experimental tests, carried out at SPLab with PSAN oxidizers synthesized in Russia, indicated that PSAN + AP mixtures (40\% PSAN and $28 \% \mathrm{AP}$ ) produce energetic formulations with steady burning rates comparable to those of AP-based propellants. Co-crystals of PSAN and AP, an innovative oxidizer produced through co-crystallization of $\mathrm{AN}$ and $\mathrm{AP}$, allow obtaining burning rates even higher than those of AP-based formulations. Cocrystals are obtained from a watery solution, where AN and AP are in the form of eutectic mixture.

This oxidizer burns at atmospheric pressure and may help to solve the problems connected with the high PDL and high pressure exponent observed in the steady burning rate analyses. These positive effects might take place due to the close contact between AN and AP particles in the eutectic mixture. Under the operating pressures typical of rocket motors, PSAN-AP or Co-cry formulations show the burning rates comparable to those of AP-based propellants (Fig. 3). 


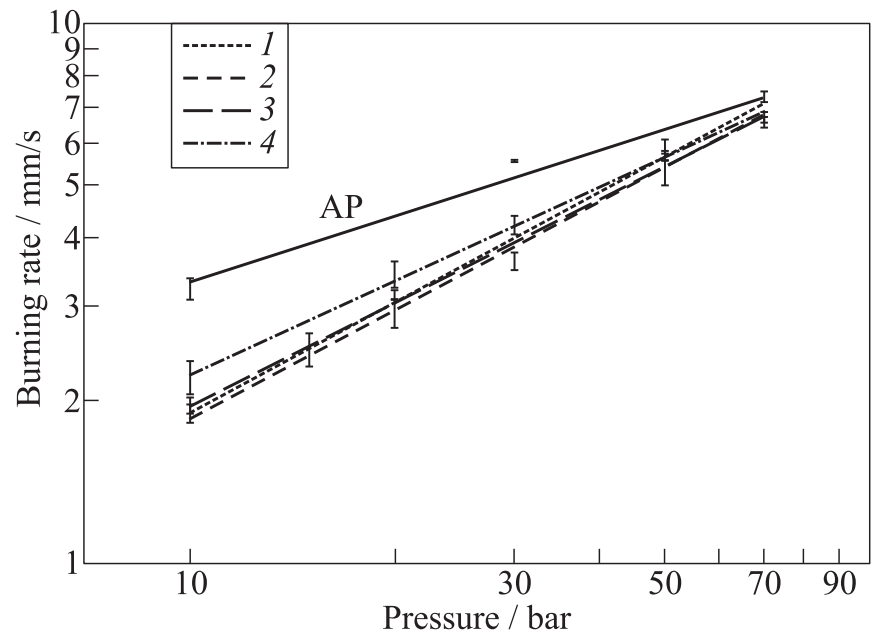

Figure 3 Comparison between the ballistic performances of PSANco-cry based propellants: 1 - PSANco-cry $(200-400), r_{b}=(0.40 \pm 0.02) p^{0.68 \pm 0.02} ; 2-$ PSANco-cry $(200), r_{b}=(0.40 \pm 0.02) p^{0.67 \pm 0.02} ; 3-$ PSANco-cry $(70), r_{b}=(0.45 \pm 0.01) p^{0.63 \pm 0.01} ;$ 4 - PSANco-cry $(\mathrm{bim}), r_{b}=(0.59 \pm 0.03) p^{0.58 \pm 0.02} ;$ and AP-based propellant, $r_{b}$ $=(1.31 \pm 0.11) p^{0.40 \pm 0.03}$

The critical aspect of the ballistic performance in PSAN-AP or Co-cry formulations is the pressure exponent which, compared to AP-based propellants, turns out to be higher also in bimodal-co-cry formulations.

To solve the problem of the high pressure exponent of PSAN formulations, a new compositions based on Co-cry with mechanical addition of AP $(\mathrm{AN} / \mathrm{AP}=0.525)$ was tested for understanding how the ballistic properties depend on increasing the AP percentage. The obtained results point out that the addition of AP implies higher burning rates but no change in the pressure exponent (Fig. 4).

On the contrary, if AP is added to the formulations through an eutectic mixture, the lower pressure exponents are found at a lower AP percentage. To verify this co-crystallization trend, a new co-crystal oxidizer synthesized at SPLab with the ratio $\mathrm{AN} / \mathrm{AP}=1$ was tested. This formulation was characterized by a pressure exponent exactly alike the characteristic value of AP formulations (Fig. 5).

The important conclusion about the ballistic performance of PSANco-cry is that co-crystallization of the eutectic mixture (PSAN + AP) allows obtaining the formulations with a ballistic behavior similar to that of AP-based propellants, but with a lower AP percentage. Regarding the pressure exponent, the optimal ratio PSAN/AP is 1 (50\% PSAN co-crystallized with $50 \%$ AP) yielding $n=0.42$. 


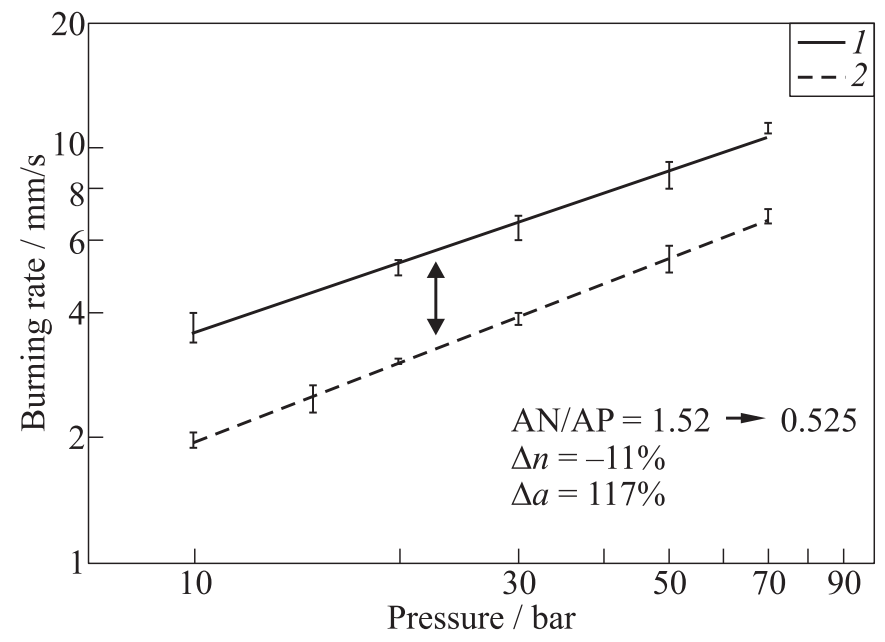

Figure 4 Comparison between the ballistic performances of PSANco-cry propellant, $r_{b}=(0.45 \pm 0.01) p^{0.63 \pm 0.01}(1)$; and PSANco-cry propellant with a mechanical AP addition to the formulation, $r_{b}=(0.98 \pm 0.06) p^{0.56 \pm 0.02}(2)$

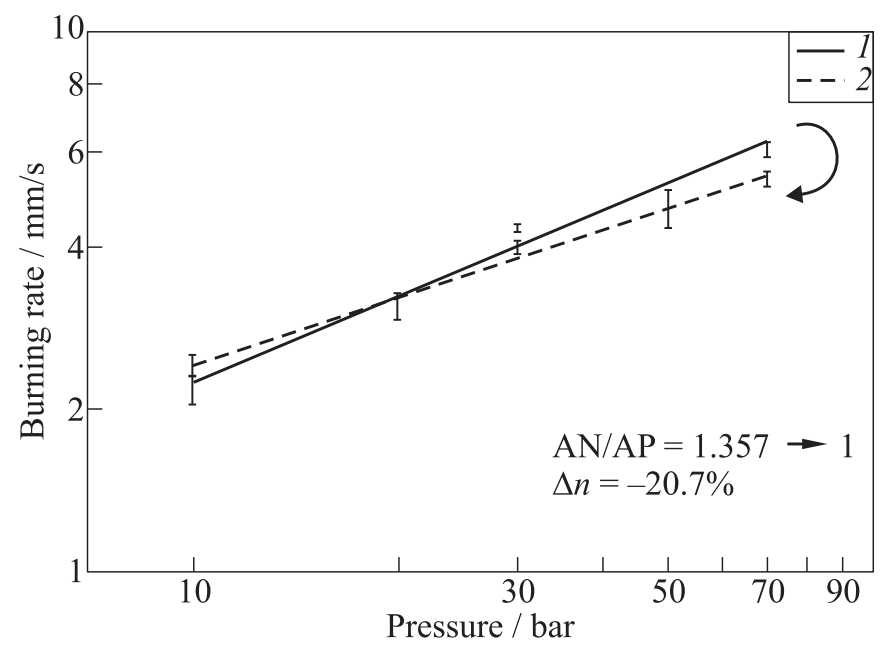

Figure 5 Comparison between the ballistic performances of a generic PSAN-AP propellant, $r_{b}=(0.60 \pm 0.04) p^{0.53 \pm 0.02}(1)$; and a PSANco-cry SPLab propellant, $r_{b}=(0.92 \pm 0.04) p^{0.42 \pm 0.01}(2)$ 


\subsection{Ignition Delay of PSANco-cry Compositions}

Ignition delay tests were carried out for PSANco-cry compositions to understand the influence of the eutectic mixture on the ignition time. Also, in terms of the ignition delay, PSANco-cry and AP formulations show a similar behavior (Fig. 6).

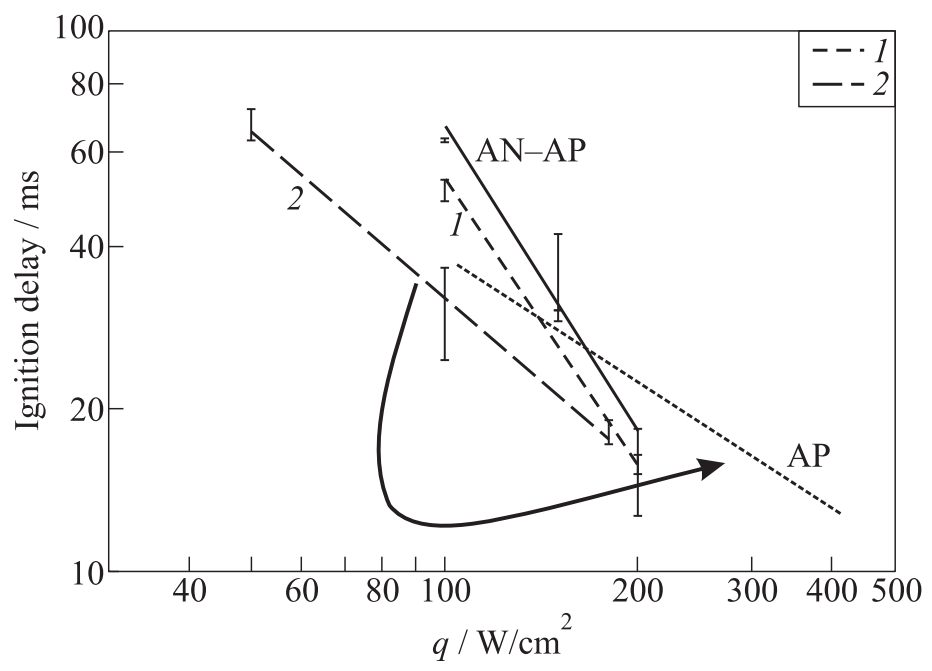

Figure 6 Ignition delays of propellants based on PSAN and PSANco-cry: 1 PSAN4-AP and 2 - PSANco-cry(bim)

\section{CONCLUDING REMARKS}

On the one hand, the $(\mathrm{AP}+\mathrm{AN})$-based propellants loaded with a bimodal $\mathrm{Al}$ mixture tend to show appealing performance using a limited fraction of $\mathrm{nAl}$ and flaked $\mu \mathrm{Al}$ instead of spherical $\mu \mathrm{Al}$. On the other hand, to reach a performance virtually equivalent to that of pure AP-based propellants, one can use a PSAN + AP co-crystallizated formulation (with 50\% PSAN $+50 \%$ AP) to strongly reduce the pollutant emissions, even if the costs are comparable to those of AP-based propellants. It is interesting to observe that with a co-crystallized oxidizer PSAN-AP, it is possible to obtain a lower pressure exponent comparable with the characteristic values for AP-based propellants. With a mechanical mixture of the oxidizer salts, instead, it is possible to obtain a higher burning rate (higher $a$ in the Vieille law) modifying the AP mass percentage, but there are no strong changes in the pressure exponent. 
At this stage of the underlying research work, it is fair to say that AN is an oxidizer potentially capable of assuring the manufacturing of ecologically safe solid propellants, but certainly further work is needed to attain acceptable costs and performance.

\section{REFERENCES}

1. Politzer, P., and P. Lane. 1998. Energetics of ammonium perchlorate decomposition steps. THEOCHEM 454(2-3):229-35.

2. Price, E. W., and R. K. Sigman. 2000. Combustion of aluminized solid propellants. In: Solid propellant chemistry, combustion, and motor interior ballistics. Progress in astronautics and aeronautics ser. Eds. V. Yang, T. B. Brill, and W.Z. Ren. AIAA Inc. 185:663-87.

3. Dokhan, A., J. M. Seitzman, E. W. Price, and R. K. Sigman. 2001. The effects of Al particle size on the burning rate and residual oxide in aluminized propellants. AIAA Paper No. 2001-3581.

4. Il'in, A.P., A. A. Gromov, and G. V. Yablunovskii. 2001. Reactivity of aluminum powders. Combust. Explosion Shock Waves 37(4):418-22.

5. Vorozhtsov, A. B., V. Arkhipov, S. Bondarchuk, N. Popok, G. Klyakin, V. Babuk, V. Kuznetsov, E. Sinogina, L. T. DeLuca, and L. Galfetti. 2005. Ballistic characteristics of solid propellants containing dual oxidizer. European Conference for Aerospace Sciences (Eucass). Moscow.

6. Babuk, V.A., A. Glebov, V.A. Arkhipov, A. B. Vorozhtsov, G. F. Klyakin, F. Severini, L. Galfetti, and L. T. DeLuca. 2005. Dual oxidizer solid rocket propellant for low-cost access to space. 10th IWCP. Bergamo, Italy: Grafiche GSS. Paper 15.

7. Miyata, K., and R. A. Frederick. 1997. Combustion mechanism of AN/AP mixedoxidizer composite propellants. AIAA Paper No. 97-3236. 